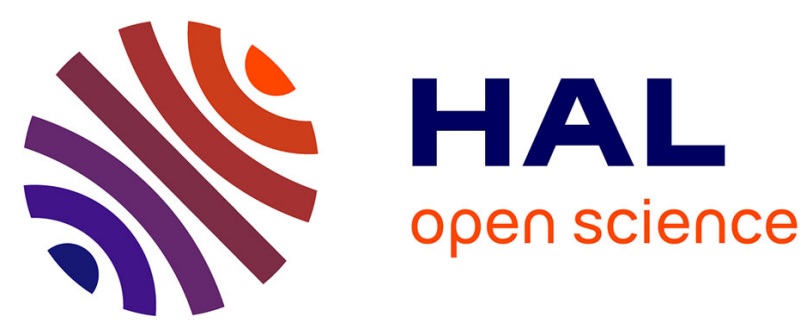

\title{
Chiral discrimination in crystalline enantiomer systems: facts, interpretations and speculations
}

\author{
A. Collet, L. Ziminski, C. Garcia, F. Vigne-Maeder
}

\section{To cite this version:}

A. Collet, L. Ziminski, C. Garcia, F. Vigne-Maeder. Chiral discrimination in crystalline enantiomer systems: facts, interpretations and speculations. Siegel J S. Supramolecular Stereochemistry, Kluwer Academic Publishers, pp.91-110, 1995, 10.1007/978-94-011-0353-4_12 . hal-00010232

\section{HAL Id: hal-00010232 \\ https://hal.science/hal-00010232}

Submitted on 28 Oct 2020

HAL is a multi-disciplinary open access archive for the deposit and dissemination of scientific research documents, whether they are published or not. The documents may come from teaching and research institutions in France or abroad, or from public or private research centers.
L'archive ouverte pluridisciplinaire HAL, est destinée au dépôt et à la diffusion de documents scientifiques de niveau recherche, publiés ou non, émanant des établissements d'enseignement et de recherche français ou étrangers, des laboratoires publics ou privés. 


\title{
CHIRAL DISCRIMINATION IN CRYSTALLINE ENANTIOMER SYSTEMS : FACTS, INTERPRETATIONS, AND SPECULATIONS
}

\author{
A. COLLET, L. ZIMINSKI, C. GARCIA, (a) AND F. VIGNÉ-MAEDER (b) \\ École normale supérieure de Lyon, (a) Stéréochimie et Interactions Moléculaires, \\ (b) Chimie Théorique \\ 69364 Lyon cedex 07, France
}

\section{Introduction}

Because it implies a perfect organization of symmetry related species, crystallization is one of the simplest and most efficient molecular recognition process. In general, a given molecule will not allow the presence of foreign molecules in its crystal lattice, and this property is widely used in the separation and purification methods based on crystallization.

Chiral molecules do not behave differently in this respect. However, the existence of a mirror image relationship between enantiomers has an important consequence : homochiral, enantiomorphous crystals, made of molecules of the same handedness, as well as heterochiral, racemic crystals, consisting of an ordered array of symmetry related right and left handed molecules, represent equally viable alternatives, from a purely crystallographic point of view.

Experimentally, this behaviour holds for the vast majority of enantiomer systems. The formation of solid solutions (pseudoracemates) between enantiomers, resulting from a lack of mutual chiral recognition, is rare and generally predictable (camphor). In most instances a racemic melt, solution, or vapor, will yield, on crystallization, either a mixture of crystals of the pure enantiomers (conglomerate), or a single racemic crystal species (racemic compound). This simple structural alternative between the two major racemate types in turn translates into the well known phase diagrams describing the solidliquid (or solid-vapor) phase equilibria that may take place in enantiomer systems (Figure 1). ${ }^{1}$

This homochiral vs. heterochiral packing alternative is by no means governed by chance; in a given set of conditions ( $T$, P, solvent), a single type of racemate - conglomerate or racemic compound - is thermodynamically allowed for a chiral molecule. Moreover, in most of the cases, the racemate type of a molecule does not change within the usual range of physical conditions to 
which it may be submitted. In somes cases, however, transformations of a racemic compound into a conglomerate (or vice versa) may occur, as for example in the conglomerate sodium ammonium tartrate (Pasteur salt) which becomes a racemic compound (Scacchi salt) over $27^{\circ} \mathrm{C}, 2$ or in the more recently studied case of $1,1^{\prime}$-binaphthyl. ${ }^{3}$
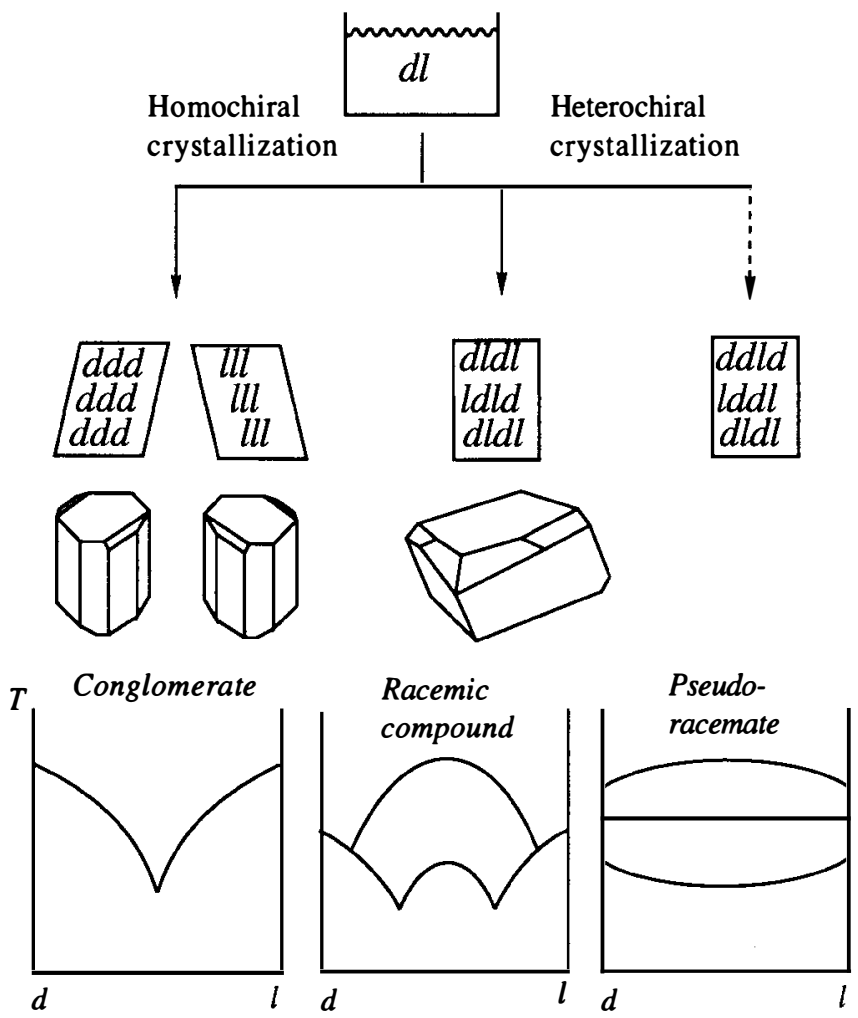

Figure 1. The homochiral vs. heterochiral packing alternative and its thermodynamical implications (phase diagrams)

If the existence of conglomerates and racemic compounds is a well established fact, it is also well accepted among the chemist community that the occurrence of these two forms is very unequal. For a long time, the fact that only a small number of conglomerates had been identified as such, has been taken as evidence that racemic compounds must be more stable than crystals made of a single enantiomer, a conclusion which was easy to accept on the basis of the old Wallach's rule (1895), 4 stating (from measurements of 8 pairs of densities) that racemic compounds are denser than their crystalline enantiomers. 
Unfortunately for this theory, a number of examples have since been discovered where a racemic compound is less dense than its enantiomers!

Are racemic compounds "generally more stable" than conglomerates and, should this statement be true, would it also imply that heterochiral crystal packings are generally more stable than their homochiral counterparts? Can we quantify the relative occurrence of the two major racemate types, and explain the prevalence of racemic compounds? Can we identify structural features, on a molecular level, that would be responsible for the formation of conglomerates, or would increase their relative frequency within series of closely related molecules? And, finaly, can we expect to alter significantly the balance between the two racemate forms by a drastic change of the physical conditions, such as the application of high pressures? These questions, some of which have recently been the object of controversial views, 5,6 are the main object of this paper.

We wish to begin, however, with another aspect of chiral discrimination in the solid state. What is the degree of tolerance of a homochiral crystal network towards substitution of chiral foreign species for its own molecules?

\section{Experiments on the co-crystallization of structurally related chiral molecules}

Homochiral crystals, made of molecules of the same handedness, cannot, in general, accept the incorporation of the opposite enantiomer in their lattice, and this is one of the reasons why optical purification of partially resolved mixtures can often be effected conveniently by crystallization. On the other hand, molecules having similar structures and sizes may co-crystallize to form solid solutions (sometimes called mixed crystals). Figure 2 shows the phase diagram corresponding to the formation of a terminal solid solution in which a small quantity of $\bigcirc$ molecules are incorporated in the lattice of the molecules.

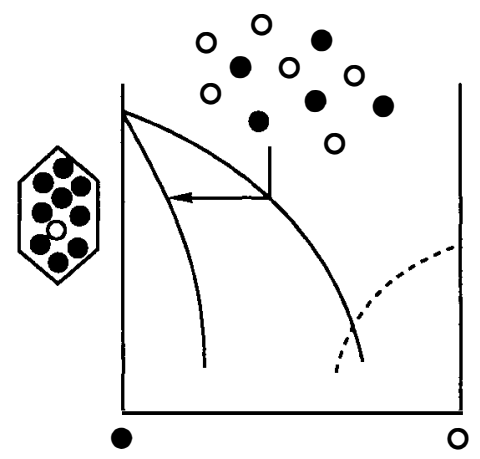

Figure 2. Terminal solid solution 
The extension of the solid solution domain in the phase diagram depends on the degree of similarity between the - and $O$ molecules and on the crystal structures of both partners. According to Kitaigorodskii, the degree of similarity of two molecules can been quantified by means of a "isosterism coefficient" $\varepsilon=1-V_{n o} / V_{o}$ where $V_{n o}$ and $V_{0}$ represent the non-overlap and overlap volume of the two molecules, respectively, when they are superposed. The value of $\varepsilon$ is 1 for identical molecules and the formation of a solid solution between two molecules would require that $\varepsilon$ be in the range 0.8 to 1 . When the crystal structures of the two species are different, only terminal solid solutions, on each side of the phase diagram, are allowed (as in Figure 2), whereas isomorphism of the two crystal species would allow the existence of a continuous series of solid solution between them if $\varepsilon$ is sufficiently close to $1 .{ }^{7}$

The isosterism coefficient can also be used as a chirality index, a way to quantify the chirality of a molecule. ${ }^{8}$ An example of the calculation of $\varepsilon$ for simple tetrahedral enantiomeric molecules is given in Figure 3. Experimentally, it is found that enantiomorphism generally precludes isomorphism; apart for the case of quasi-spherical molecules, enantiomers rarely cocrystallize, and the range of terminal solid solutions which may exist in their phase diagrams is in most cases very narrow, almost insignificant.
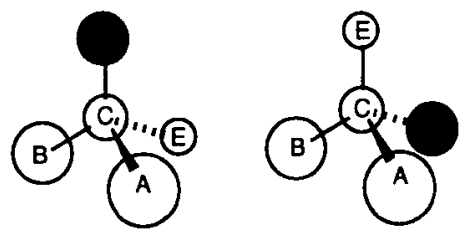

$$
\begin{aligned}
& A>B>D>E \\
& V_{o}=A+B+C+2 E \\
& V_{n o}=2(D-E) \\
& \varepsilon=1-V_{n o} / V_{0}
\end{aligned}
$$

Figure 3. Isosterism of enantiomers; the largest groups A and B and the central atom are kept superposed, a choice which is not necessarily the most pertinent

For closely related chiral molecules, such as for example $o$-chloro and $o$-bromomandelic acid, the isosterism coefficient $\varepsilon$ should be closer to 1 for the pair of the same configuration than for the pair of quasi-enantiomers (Figure 4). Accordingly, co-crystallization is expected to occur more easily between species having the same handedness, than between pairs of quasi-enantiomers (Figure 5). ${ }^{9}$ Crystallization of R-(+)-o-chloromandelic acid (as the host) in the presence of some ( \pm )-o-bromo acid (which is $3 \%$ larger in size) actually leads to a solid solution of the $\mathrm{R}-(+)$ bromo acid (ee>98\%) into the R-(+)-chloro acid lattice. 10 The crystallization of an enantiopure host in the presence of structurally related racemic guests, to form a solid solution, may thus represent a new optical resolution method. 11 Relevant (preliminary) experiments of this type are assembled in TABLE 1, from which the following conclusions may be drawn: (i) only very small amounts of the foreign species are found in the host crystal in most cases; (ii) the host lattice recognizes the size and configuration of the 
guest but is also sensitive to its chemical functionalities; (iii) excellent chiral recognition can be achieved, particularly when the guest is slightly too big.

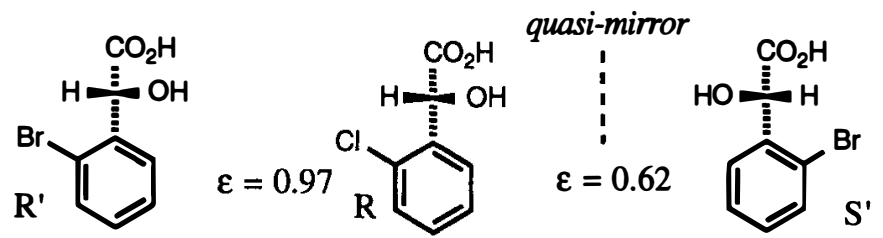

Figure 4. Isosterism between $\mathrm{R}-\mathrm{o}$-chloromandelic acid and its $\mathrm{R}$ or $\mathrm{S}$ bromo analogues
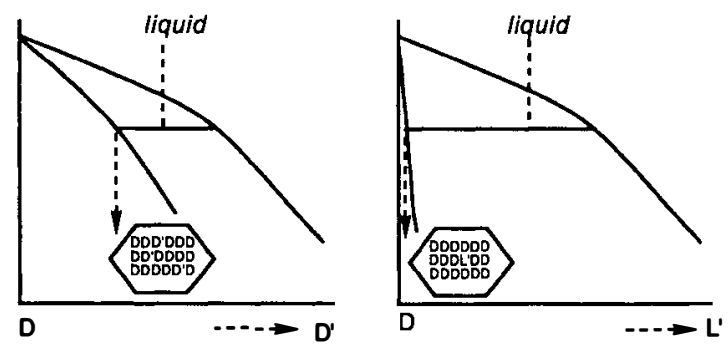

Figure 5. Co-crystallization of configurationally related (left) or opposed (right) analogues.

TABLE 1. Co-crystallization of enantiopure hosts with racemic guests

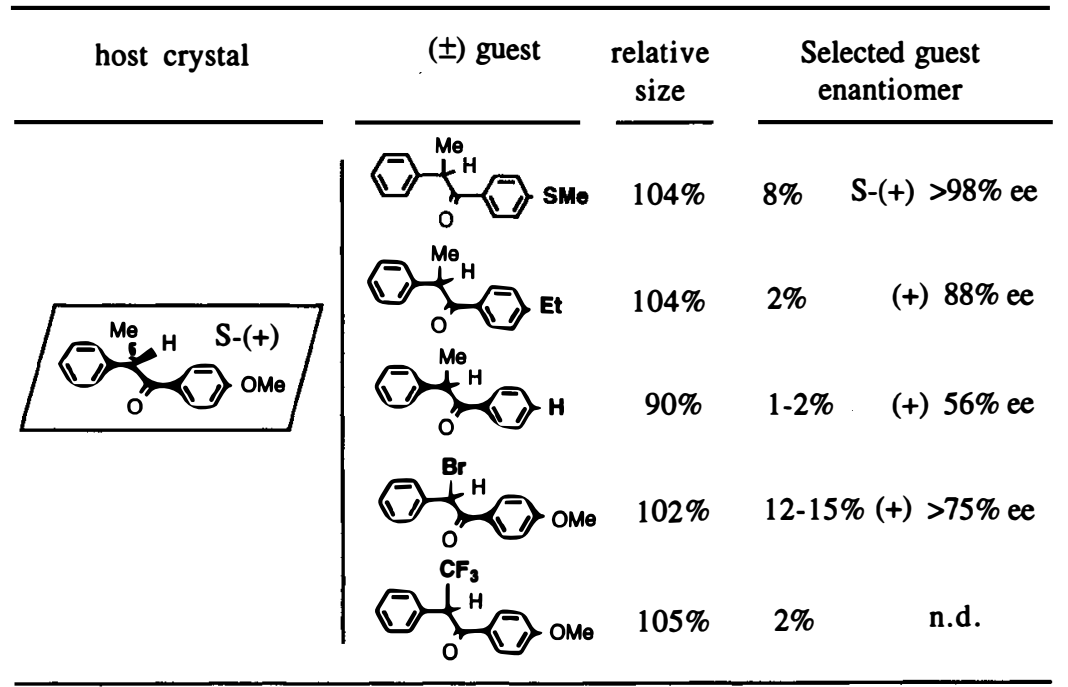


These experiments have a general bearing, in the sense that terminal solid solutions may always exist in the phase diagrams of structurally related chiral substances; in spite of their preliminary nature, they clearly suggest that molecular recognition (and chiral discrimination) performed by a rigid box (a molecular site in a crystal lattice) is a highly specific process.

It should be emphasized that host-guest solid solutions and conventional crystalline host-guest complexes, which are also used for optical resolution purposes, 12 represent basically different systems. In host-guest solid solutions, a generally small and non-stoichiometric amount of guest molecules replace host molecules in the host lattice (site substitution). The formation of such solid solutions requires that the host and the guest be sterically and configurationally related. In conventional host-guest complexes, the guest and host molecules need not be structurally related; the guest molecules fill empty spaces of the host lattice (clathrates) or occupy specific sites of the lattice (in which case stoichiometric addition complexes are obtained).

\section{The Homochiral vs. Heterochiral Packing Dilemma}

The knowledge and understanding of factors that may govern the crystallization of racemates are not only a matter of theoretical interest: one of the simplest and most efficient methods for preparing optically active materials rests on the direct crystallization of racemates existing as conglomerates. ${ }^{13,14}$

Yet, we must admit that we are still totally unable to predict the racemate type from the molecular structure, just as we are largely unable to predict the crystal structure of a molecule except perhaps in very simple cases. In fact, the homochiral or heterochiral outcome of the crystallization of a racemate is not only governed by the crystal properties, but also depends on the nature of the solid-liquid phase equilibria that occur in enantiomer mixtures. For this reason, both thermodynamic and structural aspects of the question must be taken in consideration here.

\subsection{ARE RACEMIC COMPOUNDS GENERALLY MORE STABLE THAN CONGLOMERATES?}

This question is not so trivial as it would seem, and deserves some clarification. Let us first recall (Figure 6 ) that pure enantiomers (melting separately at $T_{a}$ ) can form a conglomerate (melting at $\mathrm{T}_{\mathrm{c}}$ ) or a racemic compound (melting at $\mathrm{T}_{\mathrm{r}}$ ). Although $\mathrm{T}_{\mathrm{c}}$ is thermodynamically dependent on $\mathrm{T}_{\mathrm{a}}$ and $\Delta \mathrm{H}_{\mathrm{a}}$, the heat of fusion of a pure enantiomer (usually, $\mathrm{T}_{\mathrm{a}}-\mathrm{T}_{\mathrm{c}} \approx 25-35^{\circ} \mathrm{C}$ ), this is not the case for $\mathrm{T}_{\mathrm{r}}$ which may be lower or higher than $T_{a}$. If, however, $T_{r}$ is lower than $T_{c}$, then the racemic compound is thermodynamically less stable than the corresponding conglomerate. Although such racemic compound may occasionally exist as 
metastable forms, in most known conglomerates they do not exist at all, and this circumstance makes impossible a direct comparison of the homochiral and (hypothetical) heterochiral packings in these instances.

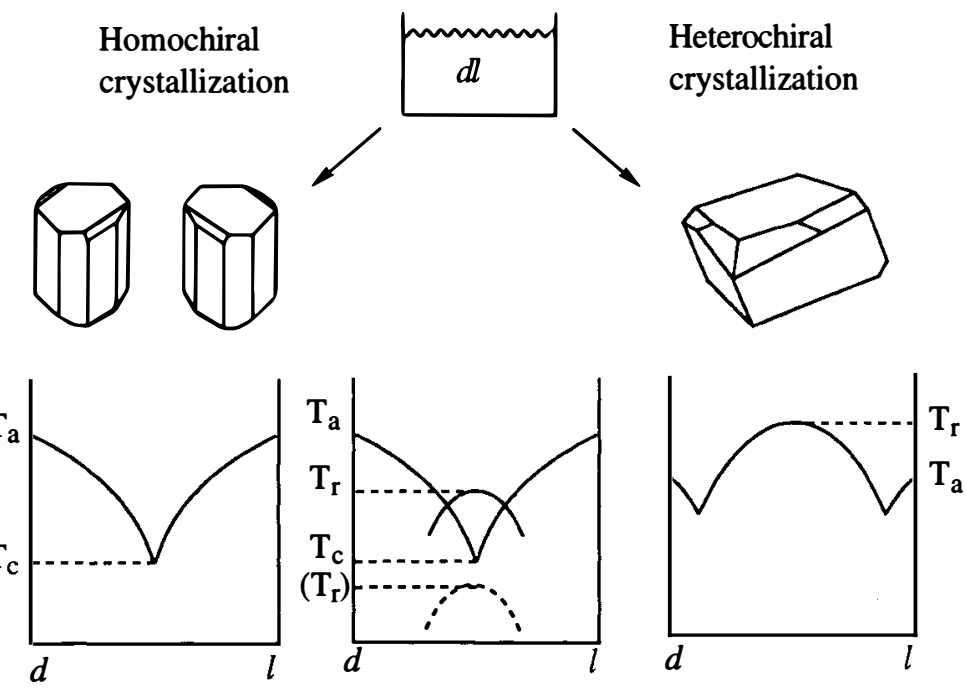

Figure 6. Solid liquid equilibria in conglomerates and racemic compounds

The statement that racemic compounds are generally more stable than conglomerates simply means that there exist much more examples of racemic compounds than of conglomerates in the presently known population of chiral molecules. Is that true, and, if yes, can we give an estimate of the relative occurrence of both forms?

These questions do not have obvious answers. If thousands of racemates have been described (who knows how many?), it is only rarely that their type has been identified and recorded in such a way that it can be retrieved. Fortunately, the fact that conglomerates melts $\approx 30{ }^{\circ} \mathrm{C}$ lower than their enantiomers may be a useful guide to identify them from literature data. This requirement naturally restricts the field of investigation to instances where the racemate and at least one enantiomer are described (natural products are virtually eliminated). Along these lines, a careful scrutiny of 1308 racemate and enantiomer pairs listed in Beilstein led to the identification of 83 conglomerates, $6 \%$ of the considered sample. ${ }^{15} \mathrm{~A}$ different approach consists of examining the racemates in series of compounds synthesized on purpose. Although this approach may be biased by the choice of the target compounds, it gave a result which is not very different from the preceding one: 194 new compounds, members of 8 different chemical families, yielded 22 conglomerates (11\%). ${ }^{16}$ 
As far as one can rely on such statistical data, they tell us that racemic compounds probably represent $90-95 \%$ of crystalline racemates.

\subsection{SOME THERMODYNAMICS}

What is the magnitude of the stability difference between a racemic compound and the corresponding conglomerate of enantiomers? A simple and certainly exact way to give an answer to this question is to define this stability difference as the free energy change $\left(\Delta G^{\circ}\right)$ of the solid state transformation of a conglomerate into its racemic compound at a temperature T.17 For a stable racemic compound, $\Delta \mathrm{G}^{\circ}$ must be negative, and, as we shall see, this statement can be experimentally verified from the melting points, enthalpies of fusion, and specific heats of the pure enantiomers and of their racemic compound, as indicated in the thermodynamic cycle of Figure 7 (where for convenience $\Delta \mathrm{G}^{\circ}=\Delta \mathrm{H}^{\circ}-\mathrm{T}_{\mathrm{r}} \Delta \mathrm{S}^{\circ}$ is calculated at $\mathrm{T}_{\mathrm{r}}$ ). Conversely, for a stable conglomerate, $\Delta \mathrm{G}^{\circ}$ as defined in Figure 7 must be positive; however, it is generally not measurable in this case because the data for the racemic compound are missing (with the exception of metastable racemic compounds).



Figure 7. Cycle allowing the calculation of the free energy of formation of racemic compounds from the conglomerate at $\mathrm{T}_{\mathrm{r}}\left(\Delta \mathrm{G}^{\circ}=\Delta \mathrm{H}^{\circ}-\mathrm{T}_{\mathrm{r}} \Delta \mathrm{S}^{\circ}\right)$. $\mathrm{Cl}^{\mathrm{l}}$ and $\mathrm{C}^{s}$ represent the specific heats $\left(\mathrm{C}_{\mathrm{p}}\right)$ of the considered liquid or solid phases.

A plot of $\Delta G^{\circ}\left(T_{r}\right)$ as a function of the melting point difference $T_{a}-T_{r}$, for a sample of 56 racemic compounds for which the necessary data are available, is shown in Figure 8. As expected, $\Delta \mathrm{G}^{\circ}$ is negative and ranges from 0 (for $\mathrm{T}_{\mathrm{a}}-\mathrm{T}_{\mathrm{r}} \approx$ 
$30 \mathrm{~K}$ ) to $\mathrm{ca}$. $-1.8 \mathrm{kcal} / \mathrm{mol}$ for the stablest racemic compounds (for which $\mathrm{T}_{\mathrm{a}}-\mathrm{T}_{\mathrm{r}}$ approaches $-80 \mathrm{~K}$ ). A striking feature of this plot is the observation of a linear correlation between $\Delta \mathrm{G}^{\circ}\left(\mathrm{T}_{\mathrm{r}}\right)$ and $\mathrm{T}_{\mathrm{a}}-\mathrm{T}_{\mathrm{r}}$; using the expressions of $\Delta \mathrm{H}^{\circ}$ and $\Delta \mathrm{S}^{\circ}$ given in Figure $7, \Delta \mathrm{G}^{\circ}\left(\mathrm{T}_{\mathrm{r}}\right)$ can be written as

$\Delta \mathrm{G}^{\circ}\left(\mathrm{T}_{\mathrm{r}}\right)=\Delta \mathrm{H}_{\mathrm{a}}-\Delta \mathrm{H}_{\mathrm{r}}-\mathrm{T}_{\mathrm{r}}\left(\Delta \mathrm{S}_{\mathrm{a}}-\Delta \mathrm{S}_{\mathrm{r}}\right)-\mathrm{T}_{\mathrm{r}} \mathrm{R} \ln 2-\left(\mathrm{Cl}^{\mathrm{l}}-\mathrm{Cs}\right)\left(\left(\mathrm{T}_{\mathrm{a}}-\mathrm{T}_{\mathrm{r}}\right)-\mathrm{T}_{\mathrm{r}} \ln \left(\mathrm{T}_{\mathrm{a}} / \mathrm{T}_{\mathrm{r}}\right)\right) ;$

rearranging this expression leads to

$\Delta G^{\circ}\left(T_{r}\right)=\left(T_{a}-T_{r}\right) \Delta S_{a}-T_{r} R \ln 2-\left(C^{l}-C s\right)\left(\left(T_{a}-T_{r}\right)-T_{r} \ln \left(T_{a} / T_{r}\right)\right) ;$

it turns out that the enthalpic and entropic contribution of the specific heats, which cannot be neglected in $\Delta \mathrm{H}^{\circ}$ and $\Delta \mathrm{S}^{\circ}$ when $\mathrm{T}_{\mathrm{a}} \neq \mathrm{T}_{\mathrm{r}}$, almost cancel each other in the above expression of $\Delta \mathrm{G}^{\circ}\left(\mathrm{T}_{\mathrm{r}}\right)$ which therefore can be simply written as

$\Delta \mathrm{G}^{\circ}\left(\mathrm{T}_{\mathrm{r}}\right)=\left(\mathrm{T}_{\mathrm{a}}-\mathrm{T}_{\mathrm{r}}\right) \Delta \mathrm{S}_{\mathrm{a}}-\mathrm{T}_{\mathrm{r}} \mathrm{R} \ln 2 ;$

the slope of the regression line $\left(15.35 \mathrm{cal} \mathrm{mol}^{-1} \mathrm{~K}^{-1}\right)$ can thus be identified with the mean entropy of fusion $\Delta S_{a}$ of the enantiomers $\left(<\Delta S_{a}\right\rangle=15.6$, esd 3.4), and $T_{r}$ similarly represents the average melting point of the racemates in the considered sample $\left(<\mathrm{T}_{\mathrm{r}}>411 \mathrm{~K}\right.$, esd $\left.41 \mathrm{~K}\right)$. In effect, the $y$ intercept of the correlation $\left(561 \mathrm{cal} \mathrm{mol}^{-1}\right)$ almost exactly equals $<\mathrm{T}_{\mathrm{r}}>\mathrm{R} \ln 2\left(566 \mathrm{cal} \mathrm{mol}^{-1}\right)$.

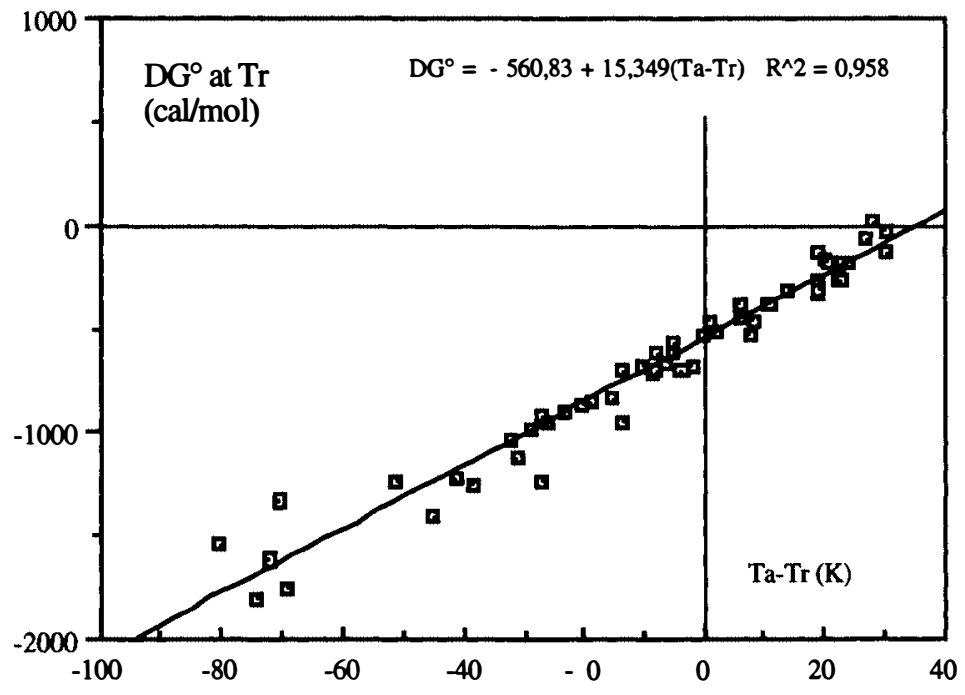

Figure 8. Plot of $\Delta G^{\circ}\left(T_{r}\right)$ as a function of $T_{a}-T_{r}$ for a sample of 56 racemic compounds.

When the pure enantiomers and the racemic compound have the same melting point (then would seem, at a first approximation, equally stable), the magnitude of the free energy of formation of the racemic compound from the 
conglomerate still amounts to ca. $-0.56 \mathrm{kcal} \mathrm{mol}^{-1}$. Here is probably the origin of the overwhelming occurrence of racemic compounds.

To give a physical interpretation of the above equations and particularly of the data distribution in Figure 8 is not an obvious matter. In the above considered sample of 56 pairs, the mean value $\left\langle\mathrm{T}_{\mathrm{r}}>411(41) \mathrm{K}\right.$ is higher by only $8 \mathrm{~K}$ than $<\mathrm{T}_{\mathrm{a}}>403(42) \mathrm{K}$. Assuming that the sample is biased by the fact that $5-10 \%$ of conglomerates are missing (for which $\mathrm{T}_{\mathrm{r}} \mathrm{T}_{\mathrm{a}}>30 \mathrm{~K}$ ), the actual difference between $\left\langle\mathrm{T}_{\mathrm{r}}\right\rangle$ and $\left\langle\mathrm{T}_{\mathrm{a}}\right\rangle$ should even be smaller than $8 \mathrm{~K}$. Based on such melting point criteria, heterochiral crystals do not seem to be stabler than their homochiral counterparts to an extent that would account for their $90-95 \%$ prevalence. In our earlier papers, $1,5,18$ we proposed that this systematic free energy difference (-TRln2) favoring the formation of the racemic compound was related to the cost of the phase separation which must occur during the crystallization of a conglomerate. This interpretation, in which $R \ln 2$, the entropy of mixing of the liquid enantiomers to give the liquid racemate, played a central role (see Figure 7), was recently challenged by Pratt Brock, Schweizer and Dunitz, 6 who pointed out that the three considered solids being ordered (enantiomer, conglomerate, and racemic compound) all have essentially the same entropy, and that for this reason the above interpretation would contradict the Third Law of thermodynamics.

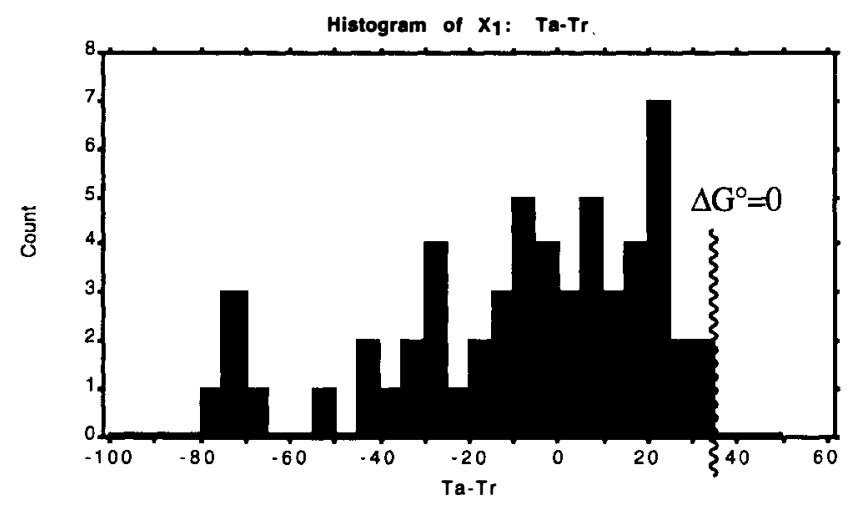

Figure 9. Frequency distribution of $\mathrm{T}_{\mathrm{a}}-\mathrm{T}_{\mathrm{r}}$ in 56 racemic compounds.

A (possibly not) less controversial interpretation is the following. The racemic compound is in equilibrium with a liquid of the same composition, whereas in a conglomerate each pure enantiomer crystal is in equilibrium with a liquid that does not match its composition ( $\mathrm{x}_{d}$ or $\mathrm{x}_{l}=0.5$ in the liquid instead of 1 in the solid). For this reason, the equilibrium temperature for a conglomerate in its racemic liquid is lowered by $\approx 30 \mathrm{~K}$ with respect to that of the enantiomers in their respective pure liquids. As we have seen above, the mean value of $T_{r}$ and that of $T_{a}$ are not very different. On a statistical basis, one may 
expect that the frequency of the conglomerates will be related to the histogram of Figure 9, where the frequency distribution of $T_{a}-T_{r}$ in the 56 considered pairs is shown. The fraction of these racemic compounds having $T_{a}-T_{r}$ in the region of 25 to $35 \mathrm{~K}$ of the histogram (i.e., those which deviate from the mean value by 23 to $33 \mathrm{~K}$ ) is indeed very small. Furthermore, the fact that their number decreases rapidly as the negative value of $T_{a}-T_{r}$ increases means that the probability of finding racemic compound with positive $\Delta G^{\circ}$ is low, which is consistent with the observed low frequency of the conglomerates.

\subsection{STABILITY, CRYSTAL DENSITY AND WALLACH'S RULE}

The fact that racemic compounds are more stable than their conglomerates in 9095\% of the cases does not mean that homochiral packing are generally less stable than their heterochiral variant. This statement can be easily verified if other criteria than the relative occurrence of the two racemate forms are considered. In the three specific examples of hydroxyacids 1-3 assembled in TABLE 2, the racemic compounds are all less dense than the enantiomer crystals, and, in 2 , the enthalpy of formation of the racemic compound $\left(\Delta \mathrm{H}^{\circ}\right.$, as defined in Figure 8) is even positive. In this case the homochiral packing is both more compact and enthalpically more stable than the racemic compound, although in equilibrium with its racemic liquid the latter is thermodynamically favored.

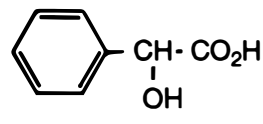

1

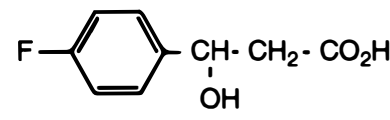

2

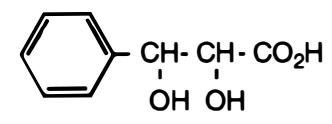

3

TABLE 2. Thermodynamic data and crystal densities for hydroxyacids 1-3

\begin{tabular}{rrrrrrrr}
\hline & $\mathrm{T}_{\mathrm{a}}$ & $\mathrm{T}_{\mathrm{r}}$ & $\Delta \mathrm{H}^{\circ}$ & $\begin{array}{c}\mathrm{T}_{\mathrm{r}} \Delta \mathrm{S}^{\circ} \\
(\mathrm{cal} / \mathrm{mol})\end{array}$ & $\Delta \mathrm{G}^{\circ}\left(\mathrm{T}_{\mathrm{r}}\right)$ & $\mathrm{d}_{\mathrm{a}}$ & $\mathrm{d}_{\mathrm{r}}$ \\
\hline $\mathbf{1}$ & 406 & 392 & -80 & +250 & -330 & 1.350 & 1.320 \\
$\mathbf{2}$ & 381 & 362 & +325 & +470 & -145 & 1.417 & 1.390 \\
$\mathbf{3}$ & 371 & 395 & -1240 & -320 & -920 & 1.400 & 1.365 \\
\hline
\end{tabular}

Several compilations of racemic and enantiomer pairs for which crystallographic data are available have been reported; they allow a much more accurate comparison of crystal densities than those obtained by Wallach a century ago. In the first of these lists reported by Jacques, Collet and Wilen, 1 and containing 14 pairs of structures, the average density variation ${ }^{19}$ on going from the enantiomer to the racemic crystal $\Delta \%$ is $-1.2(9) \%$, with 9 of the 14 
racemic compounds being less dense than their enantiomers. In a similar compilation by Mason, 20 listing 14 pairs which partially overlap the previous list, the average of $\Delta \%$ is $+2.2(13)$, with 5 of the 14 racemic compound being less dense than their chiral counterparts.

A more recent compilation, based on the Cambridge Structural Database, 21 was reported by Pratt Brock, Schweizer and Dunitz. 6 For 129 pairs, they found 53 racemates less dense than their enantiomers, the average of $\Delta \%$ being $+0.56(22) \%$, a deviation from zero which was considered to be 'hardly large enough to be convincing, but (...) too large to ignore'. If these studies demonstrate that, stricto sensu, Wallach's rule does not hold, they also raise the question of the existence of a relation between the magnitude of $\Delta \%$ and that of $\Delta G^{\circ}\left(T_{r}\right)$ for pairs of racemic and enantiomer crystals. That such a relation indeed exists is suggested by reconsidering the data of Pratt Brock et al. in the light of the above discussed thermodynamic analysis.

Their sample of 129 pair actually consists of two groups of molecules, Group I (64 pairs) containing rapidly interconverting enantiomers, 22 and Group II (65 pairs) consisting of resolvable enantiomers (Figure 10).
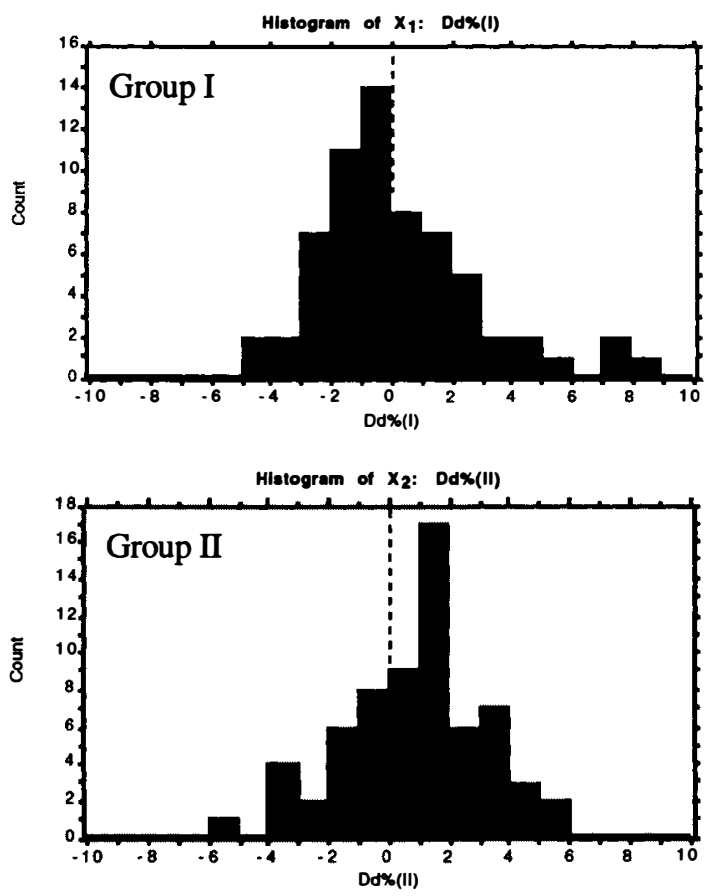

Figure 10. Distribution of $\Delta \%$ in Group I and Group II subpopulation of 129 racemic and enantiomer crystal pairs (after Pratt Brock et al., ref 6) 
In Group I, 32 of the 64 pairs have $d_{r}<d_{a}$, and the average of $\Delta \%$ is reduced to $+0.20(34) \%$, i.e., almost zero. In Group II, in which only 21 of the 65 pairs have $\mathrm{d}_{\mathrm{r}}<\mathrm{d}_{\mathrm{a}}$, the average of $\Delta \%$ is increased to $+0.92(29) \%$. Pratt Brock et al. attributed this difference between the two groups to a statistical bias in Group II population, 'since this can contain only pairs in which the racemic crystal is markedly more stable than the chiral one (...) but no pairs in which the racemic crystals are markedly more stable'. We disagree with this interpretation. In our opinion, Group II is not more biased than any other sample of this kind, in the sense that it must be representative for $90-95 \%$ of the racemates.

On the other hand, Group I, which Pratt Brock et al. consider as non-biased is, in our opinion, totally biased: this group in which enantiomers are rapidly interconverting in the liquid phase can only contain pairs for which enantiomer and racemic crystals have the same stability when they are in equilibrium with the racemic liquid, otherwise one of the forms would not be observable. The equilibrium temperature that must be considered here is therefore that of the eutectic (conglomerate) of the two enantiomers, and the melting points of the racemic compounds of this sample should be equal (or at least close) to those of the corresponding conglomerates. Accordingly, for all racemates of Group I, $\Delta G^{\circ}\left(T_{r}\right)$ should be close to zero (Figure 8 ). By contrast, the average of $\Delta G^{\circ}\left(T_{r}\right)$ for the racemates of Group II should be negative; for comparison, the average $<\Delta \mathrm{G}^{\circ}\left(\mathrm{T}_{\mathrm{r}}\right)>$ in the 56 pairs of Figure 8 is $-0.69 \mathrm{kcal} / \mathrm{mol}$, a figure which slightly exceeds the boundary of $-0.56 \mathrm{kcal} / \mathrm{mol}$ below which we consider that the homochiral packing is more stable than the heterochiral one. The fact that the average of $\Delta \%$ increases on going from Group I to Group II subpopulations is entirely consistent with the expected variation of $\left\langle\Delta G^{\circ}\left(T_{r}\right)\right\rangle$ between them.

\subsection{MOLECULAR STRUCTURE AND RACEMATE STABILITY}

The existence of series of structurally related compounds in which the occurrence of conglomerates seems to be greater than the average, and, on the contrary, of structural families where no examples of conglomerates have ever been reported, has nothing really astonishing. On a macroscopic level, the bissection of a cube (or a sphere) into halves of $\mathrm{C} 2$ symmetry gives two fragments having the same handedness, while a similar cut into halves of C3 symmetry yields two fragments of opposite handedness. Conversely, two homochiral object of C2 symmetry can form a close packed dimer in which their twofold axes are aligned, while a similar close packing of $\mathrm{C} 3$ object is heterochiral. This observation, 23 which takes its origin from a long practice of Horeau's Coupe du Roi, has for some time led Jacques and his coworkers to the (hitherto unconfirmed) belief that molecules having a twofold axis would form conglomerates more often that molecules devoid of this symmetry element. 24 Unfortunately, on a molecular level things seems a bit more complicated, perhaps because the magnitude of the energy difference between homochiral and heterochiral packings is small compared with the total lattice energy of a crystal.

Nevertheless, there are perhaps a few structural families where a relatively clear picture seems to emerge: simple carboxylic acids, such as 2-arylpropionic 
acids or 2-aryloxypropionic acids, which are devoid of H-bonding groups other than the carboxylic function, invariably form very stable racemic compounds. In contrast, their salts show an opposite behaviour, i.e., form racemic compounds of weak stability, and for this reason the formation of salts has been suggested as a way to increase the chance of finding new conglomerates. 15

The above discussed sample of 56 racemates contains a subset of seven $o, m, p$-chloro and nitro 2-phenoxypropionic acids and 18 of their salts with achiral amines. A plot of $\Delta \mathrm{G}^{\circ} v s$. $\left(\mathrm{T}_{\mathrm{a}}-\mathrm{T}_{\mathrm{r}}\right)$ for this subset illustrate this trend; the average $\left\langle\Delta \mathrm{G}^{\circ}\left(\mathrm{T}_{\mathrm{r}}\right)\right\rangle$ is $-0.97(27) \mathrm{kcal} / \mathrm{mol}$ for the acids, a value reduced to $-0.53(30) \mathrm{kcal} / \mathrm{mol}$ for their salts (Figure 11). Aromatic hydroxy acids (such as 1-3 above and their congeners) exhibit the same behaviour as the salts of these 2-phenoxypropionic acids; a comparatively high frequency of conglomerates has been found among their racemates. 1,25

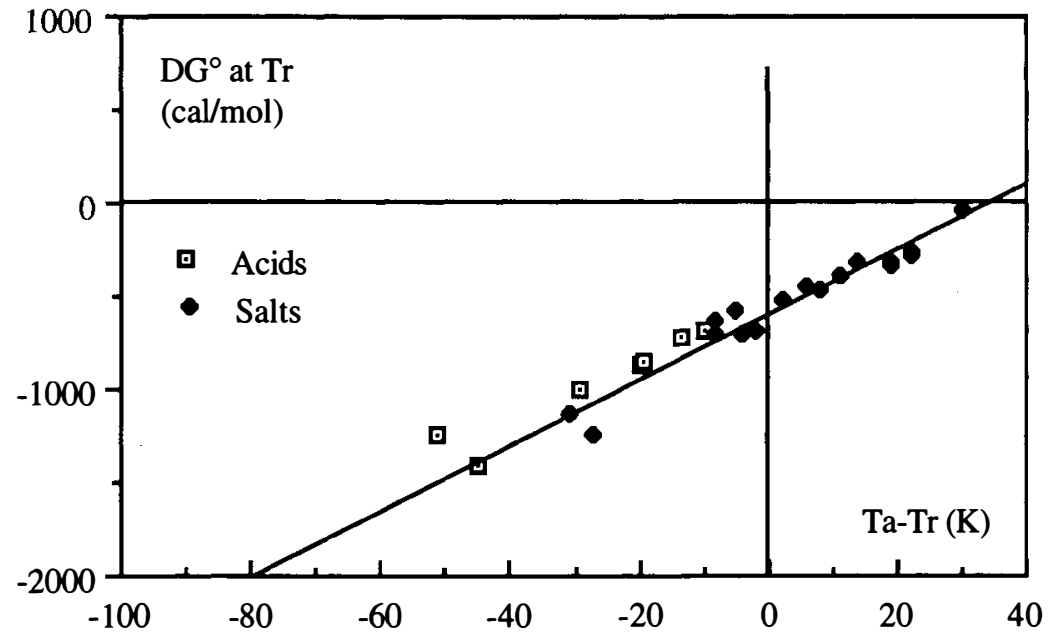

Figure 11. $\Delta \mathrm{G}^{\circ}\left(\mathrm{T}_{\mathrm{r}}\right)$ vs. $\left(\mathrm{T}_{\mathrm{a}}-\mathrm{T}_{\mathrm{r}}\right)$ in subpopulations of the 56 racemates of Figure 8.

A general interpretation of these observations has been advanced.5,15,18 Enantiomers which can form centrosymmetric pairs on crystallization will always form heterochiral lattices that are more efficiently packed than those of their homochiral counterparts. Simple carboxylic acids typically show this behaviour (for these compounds, Wallach's rule holds). When, on the other hand, the formation of centrosymmetric dimers is made impossible for structural reasons, then homochiral and heterochiral packings will not differ much in energy, and this will result in a shift of the average magnitude of $\Delta \mathrm{G}^{\circ}$ towards lower values, approaching the thermodynamic domain of the conglomerates. In support to this view, it has been observed that racemic aromatic hydroxyacids as 
well as carboxylic acid salts form crystals dominated by complex H-bonding patterns in which centrosymmetric dimer are generally absent. 25

In theory, suitable lattice energy calculations may provide new insights into these questions. The first general approach of this kind, addressing the crystallization of chiral molecules, was suggestd by Zorkii in the late sixties, 26 in the line of the ideas of Kitaigorodskii and his school.27 Given the shape and symmetry of the considered molecule, only a few number of space groups would be permitted, among them variants corresponding to racemic and enantiomer structures; for each variant, the free energy is calculated as a function of structural parameters (lattice dimensions, location and orientation of the molecules in the cell). Calculation of this type have been described in 1990 by Saigo and coworkers, 28 in the cases of alanine, valine, and trans 1,2-cyclohexanecarboxylic acid (all forming racemic compounds), and of 1-phenylethylammonium and 1-(4-isopropylphenyl)ammonium cinnamates (both salts forming conglomerates). Even though the calculations correctly predicted the racemate type in all cases, the general validity of such approach rests not only on the elaboration of a suitable methodology for the builing up of hypothetical crystal structures, but also on the availability of reliable procedures for the calculation of intermolecular potential energies in molecular crystals. In this domain much progress have still to be done 29 before crystal structures become predictable from molecular structures alone. 30,31

\section{A Prediction: Crystallization Under High Pressure Should Increase the Occurrence of Conglomerates}

The observation that $\approx 40 \%$ of the racemic compounds do not follow Wallach's rule has an interesting physical consequence. Since in these cases the transformation of a racemic compound into its conglomerate would be attended by a reduction of the cell volume, a simple application of Le Chatelier's principle suggests that this process could take place under high pressure. What would be the order of magnitude of the pressure required to achieve this transformation?

Clapeyron equation (Figure 12) tells us that the slope of the solid liquid boundary in a $(\mathrm{P}, \mathrm{T})$ phase diagram depends on $\Delta \mathrm{H}^{\mathrm{f}}$, the molar enthalpy of fusion $(>0)$, and $\Delta \mathrm{Vf}$, the molar volume change on melting. In general, the slope of this boundary is positive because $\Delta \mathrm{Vf}=\mathrm{Vl}$ - Vs is positive (water is an exception), and this is why the melting point of most compounds actually increases with pressure.

For chiral molecules, the molar volumes of enantiomer and racemic liquids are virtually identical (ideal systems), and hence, for the cases which do not follow Wallach's rule, $\left(\mathrm{Vl}^{\mathrm{l}} \mathrm{Vs}\right) \mathrm{a}$, the molar volume increase of an enantiomer on melting, will be greater than $\left(\mathrm{Vl}^{\mathrm{l}}-\mathrm{Vs}\right) \mathrm{r}$, the corresponding quantity for the racemic compound. The slopes of their respective solid liquid boundaries in the $(\mathrm{P}, \mathrm{T})$ diagram will therefore be different from one another (Figure 13). For the 
same pressure increase, the melting point of the enantiomers, and that of their conglomerate, increase more rapidly than the melting point of the racemic compound, and there exist a transition pressure $P_{\text {trans }}$ beyond which the melting point of the latter becomes lower than that of the conglomerate, which then becomes the stable crystal form of the considered racemate.

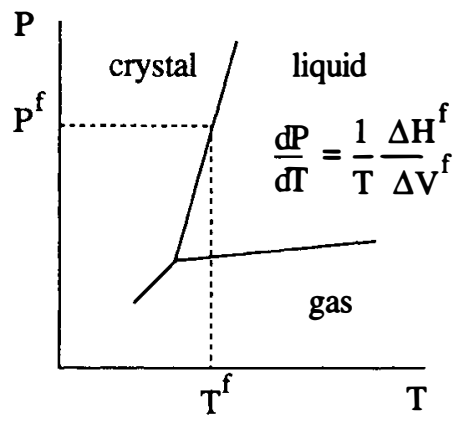

Figure 12. Clapeyron equation
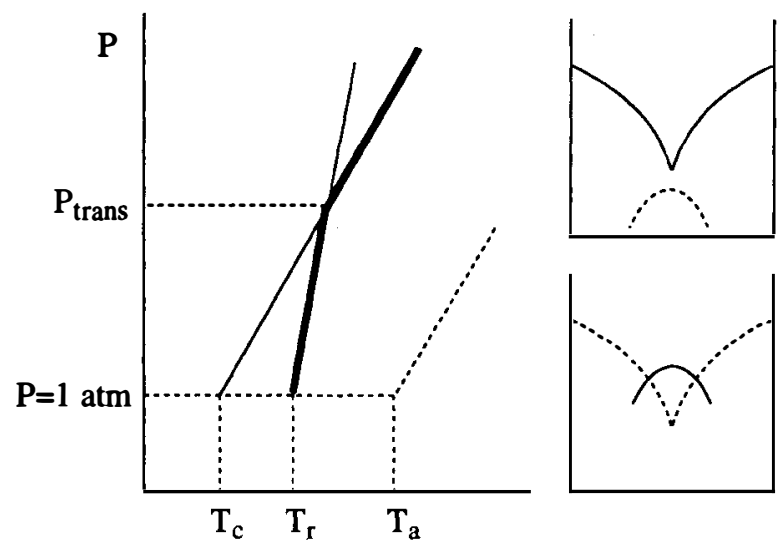

Figure 13. Pressure induced transition of a racemic compound to a conglomerate

In order to evaluate the magnitude of $P_{\text {trans, }}$ it is necessary to incorporate into the Schröder-van Laar and Prigogine-Defay equation, which describe the liquidus curves in the binary phase diagrams of enantiomer mixtures, ${ }^{1}$ the effect of the pressure; this can be done by means of the Clapeyron equation. Assuming that the enthalpies of fusion $\left(\Delta \mathrm{H}_{\mathrm{a}}\right.$ and $\left.\Delta \mathrm{H}_{\mathrm{r}}\right)$ as well as the molar volume 
changes $\left(\Delta V_{\mathrm{a}}\right.$ and $\left.\Delta \mathrm{V}_{\mathrm{r}}\right)$ for the pure enantiomer and the racemic compound, respectively, are independent from $\mathrm{T}$ and $\mathrm{P}, 32$ we thus arrive at the following modified equations, from which the binary melting points of enantiomer mixtures can be calculated as a function of the applied pressure:

$\ln (x)=\frac{\Delta \mathrm{H}_{\mathrm{a}}}{R}\left(\frac{1}{\mathrm{~T}_{\mathrm{a}\left(\mathrm{P}_{0}\right)}}-\frac{1}{\mathrm{~T}}\right)-\frac{\Delta \mathrm{V}_{\mathrm{a}}}{R \mathrm{~T}}\left(\mathrm{P}-\mathrm{P}_{0}\right)$

which describes the liquidus curve of the enantiomers, and

$\ln (4 x(1-x))=\frac{2 \Delta \mathrm{H}_{\mathrm{r}}}{R}\left(\frac{1}{\mathrm{~T}_{\mathrm{r}\left(\mathrm{P}_{0}\right)}}-\frac{1}{\mathrm{~T}}\right)-\frac{2 \Delta \mathrm{V}_{\mathrm{r}}}{R \mathrm{~T}}\left(\mathrm{P}-\mathrm{P}_{0}\right)$

which describes the liquidus of the racemic compound.

The phase diagrams of mandelic acid and erythro-phenylglyceric acid (compounds 1 and 3 above) were calculated as a function of pressure using these equations and the data of TABLE 2 (Figure 14). The unknown molar volume of the liquids was estimated on the assumption that the average molar increase on melting is $16 \%$.
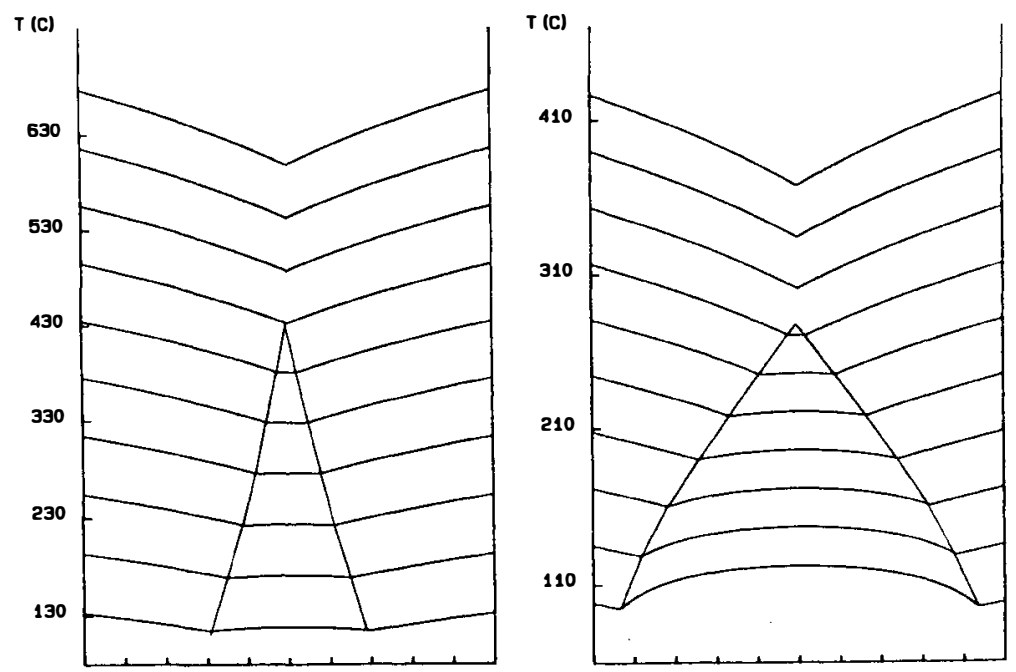

Figure 14. Melting point phase diagrams of mandelic acid 1

(left) in the range of 0-18 kbar, and of phenylglyceric acid 3 (right) in the range of 0-9 kbar (See Table 2).

Mandelic acid, for which the enantiomer crystal is $2.3 \%$ denser than the racemic compound at normal pressure, is thus predicted to become a 
conglomerate at $\approx 12 \mathrm{kbar}$, with a conglomerate melting point $\mathrm{T}_{\mathrm{c}} \approx 500{ }^{\circ} \mathrm{C}$. Phenylglyceric acid, with a density difference of $2.6 \%$, is similarly predicted to be a conglomerate above $7 \mathrm{kbar}$, with $\mathrm{T}_{\mathrm{c}}$ at the transition pressure around $300{ }^{\circ} \mathrm{C}$.

Although these pressures are easily accessible, e.g., by means of diamond cells, the above predictions do not seem to have given rise to experimental verifications at the time (1994) this paper is written. Should these views appear to be correct, then the question of the behaviour of chiral systems under high temperature and pressure conditions such as those existing in hydrothermal systems would certainly merit study. In such conditions, the occurrence of conglomerates might become as high as $30-40 \%$ ! Combination of temperature promoted racemization (like in the case of 1,1'-binaphtyl) with pressure induced spontaneous resolution could then represent a new mechanism for the generation of optical activity, that does not seem to have been considered so far.

\section{References}

1 Jacques J., Collet A. and Wilen S. H., (1981) Enantiomers, Racemates, and Resolutions, Wiley, New York.

2 Kuroda R. and Mason S. F. (1981) Crystal structures of dextrorotatory and racemic sodium ammonium tartrate, J. Chem. Soc., Dalton Trans., 12681273.

3 Kress R. B., Duesler E. N., Etter M. C., Paul I. C., and Curtin D. A. (1980) Solid-state resolution of binaphthyl: crystal and molecular structure of the chiral (A) form and racemic (B) form and the study of the rearrangement of single crystals. Requirements for the development of hemihedral faces for enantiomer identification, J. Am. Chem. Soc., 102, 7709-7714 and refs therein.

4 Wallach, O (1895) Zur Kenntniss der Terpene und der ätherischen Oele, Liebigs Ann. Chem., 286, 90-143 (see p 140).

5 Collet, A. (1990) The homochiral versus heterochiral packing dilemma, in M. Simonyi (ed), Problems and wonders of chiral molecules, Akademiai Kiado, Budapest, pp 91-109.

6 Pratt Brock C., Schweizer W. B. and Dunitz J. D. (1991) On the validity of Wallach's rule: on the density and stability of racemic crystals compared with their chiral counterparts, J. Am. Chem. Soc., 113, 9811-9820.

7 A. I. Kitaigorodskii, Organic Chemical Crystallography, Consultant Bureau, New York, 1961, p. 230.

8 Chion B., Lajzerowicz J., Bordeaux D., Collet A. and Jacques J. (1978) Structural aspects of solid solutions of enantiomers, J. Phys. Chem., 82, 2682-2688. See also: Buda A. B., Auf der Heyde T., and Mislow K. (1992) On quantifying chirality, Angew. Chem. Intern. Ed. Engl., 31, 989-1007. 
9 Stucturally related molecules of opposite configurations may also form quasi-racemates; see ref. 1, p 100, and for example, Fredga A., (1960) Tetrahedron , 8, 126.

10 Garcia C. and Collet A. (1992) unpublished results; presented at the 3rd International Symposium on Chiral Discrimination, Tubingen, Germany.

11 Garcia, C. and Collet A. (1992) New optical resolution method based on the formation of a solid solution, Tetrahedron:Asymmetry 3, 361 .

12 Toda F. (1987) Isolation and optical resolution of materials utilizing inclusion crystallization,Topics Curr. Chem., 140, 43-69.

13 Collet A. (1995) Optical resolution in Comprehensive supramolecular chemistry, Vol. 10, Reinhoudt D. N. ed., Pergamon, Oxford (in press).

14 Collet A., Brienne M. J. and Jacques J. (1981) Optical resolution by direct crystallization of enantiomer mixtures, Chem. $\operatorname{Rev} .80,215$.

15 Jacques J., Leclercq M. and Brienne M. J. (1981) La formation de sels augmente-t-elle la fréquence des dédoublements spontanés? Tetrahedron 37 , 1727-1733.

16 Details will be given elsewhere.

17 Leclercq M., Collet A., and Jacques J. (1976) Étude des mélanges d'antipodes optique-XII. Mesure de la stabilité des racémiques vrais, Tetrahedron 32, 821-828.

18 Gabard J. and Collet A. (1986) Purification d'acides partiellement dédoublés par l'intermédiaire de sels d'amines achirales. Théorie et application aux acides 2-phénoxypropioniques, Nouv. J. Chim. 10, 685-690.

19 Defined as $\Delta \%=100\left(\mathrm{~d}_{\mathrm{r}}-\mathrm{d}_{\mathrm{a}}\right) /\left[0.5\left(\mathrm{~d}_{\mathrm{r}}+\mathrm{d}_{\mathrm{a}}\right)\right]($ ref 6$)$.

20 Mason S. F. (1982) Molecular optical activity and the chiral discriminations, Cambridge University Press, p 171.

21 Allen F. H., Kennard O., and Taylor R. (1983) Acc. Chem. Res. 16, 146153.

22 Group I also contain achiral molecules that may form both chiral and achiral crystals. In our opinion these cases should be considered separately, because in these compounds the liquid which is in equilibrium with the solid at the melting point is a pure component, whereas in the other cases of this group the liquid always has a racemic composition.

23 Brienne M. J. and Jacques J. (1975) Remarques sur la chiralité de certains clathrates du type cage, Tetrahedron Lett. 2349-2352.

24 Collet A., Brienne M. J. and Jacques J. (1972) Dédoublements spontanés et conglomérats d'énantiomères, Bull. Soc. Chim. Fr., 127-142; ibid., 336342.

25 Cesario M., Guilhem J., Pascard C., Collet A. and Jacques J. (1978) Structures cristallines et dédoublements spontanés: étude d'une famille d'hydroxyacides aromatiques, Nouv. J. Chim. 2, 343-349. 
26 Zorkii P. M. (1968), Soviet. Phys. Crystallogr. 13, 19. See ref 1 p 30.

27 Perstin A. J. and Kitaigorodskii A. I. (1987), The atom-atom potential model, Springer-Verlag, Berlin.

28 Kimoto H., Saigo K. and Hasegawa M. (1990) The potential energy calculation for conglomerate crystals, Chemistry Letters, 711-714.

29 For example, see: Gavezzoti A. (1990) Packing analysis of organic crystals containing $\mathrm{C}=\mathrm{O}$ and $\mathrm{C} \equiv \mathrm{N}$ groups, J. Phys. Chem. 94, 4319-4325.

30 Gavezzoti A. (1991) Generation of possible crystal structures from the molecular structure for low polarity organic compounds, J. Am. Chem. Soc. 113, 4622-4629.

31 Perlstein J. (1994) Molecular self assemblies. 2. A computational method for the prediction of the structure of one-dimensional screw, glide, and inversion molecular aggregates and implications for the packing of molecules in monolayers and crystals, J. Am. Chem. Soc. 116, 455-470.

32 Strictly speaking these assumptions, and particularly that concerning the enthalpies, are not valid; however, in the present case, we may assume that the variation with pressure of the differences $\Delta \mathrm{H}_{\mathrm{a}}-\Delta \mathrm{H}_{\mathrm{a}}$ and $\Delta \mathrm{V}_{\mathrm{a}}-\Delta \mathrm{V}_{\mathrm{r}}$ are small, and hence that the intersection of the two liquidus curves as calculated by the modified equations are roughly correct. 